\title{
O papel do Orientador Educacional na visão dos Profissionais da Escola
}

\author{
The role of the Educational Advisor in the view of the School's Professionals \\ El rol del Asesor Educativo en la visión de los Profesionales de la Escuela
}

Recebido: 15/06/2021 | Revisado:20/06/2021 | Aceito: 21/06/2021 | Publicado: 55/07/2021

\author{
Joana Laura de Castro Martins \\ ORCID: https://orcid.org/0000-0002-8106-2371 \\ Universidade Federal de Santa Maria, Brasil \\ E-mail: joanalauradecastro@ hotmail.com \\ Tauane Farias Telles Stamm \\ ORCID: https://orcid.org/0000-0002-8400-1873 \\ Universidade do Vale do Rio dos Sinos, Brasil \\ E-mail: tauaneftelles@gmail.com
}

\begin{abstract}
Resumo
Este trabalho de conclusão de curso propõe analisar as ações tomadas pelo Orientador Educacional na visão dos profissionais da Escola de Educação Básica. Para tanto, aplicou-se um questionário digital semi - estruturado com professores do ensino fundamental de escolas públicas do município de Parobé no Estado do Rio Grande do Sul. Visando elencar as ações tomadas pelos orientadores educacionais diante dos problemas observados no contexto escolar e identificar como essas ações podem contribuir ou até mesmo prejudicar o processo de ensino-aprendizagem dos alunos. Muitos professores têm dúvidas sobre qual o papel do Orientador e isso dificulta sua atuação com os discentes, visto que situações que precisariam de sua intervenção podem acabar sendo negligenciadas, por não serem levadas até o Orientador. Por fim, observou-se a importância de se estabelecer um relacionamento harmonioso entre os sujeitos que compõem a comunidade escolar para que o trabalho de todas as partes envolvidas possa se concretizar de maneira mais efetiva e satisfatória.
\end{abstract}

Palavras-chave: Orientação educacional; Ação docente; Assistência efetiva; Ensino.

\begin{abstract}
This course conclusion work proposes to analyze the actions taken by the Educational Advisor in the view of the Basic Education School professionals. Therefore, a semi-structured digital questionnaire was applied to elementary school teachers from public schools in the municipality of Parobé in the State of Rio Grande do Sul. Aiming to list the actions taken by educational advisors in the face of problems observed in the school context and identify how these actions can contribute or even harm the students' teaching-learning process. Many teachers have doubts about the role of the Advisor and this makes it difficult for them to act with the students, since situations that would need their intervention may end up being neglected, as they are not taken to the Advisor. Finally, it was observed the importance of establishing a harmonious relationship between the subjects that make up the school community so that the work of all involved parties can be carried out in a more effective and satisfying way.
\end{abstract}

Keywords: Educational orientation; Teaching action; Effective assistance; Teaching.

\section{Resumen}

El trabajo de conclusión de este curso propone analizar las acciones realizadas por el Asesor Educativo desde la perspectiva de los profesionales de la Escuela de Educación Básica. Por lo tanto, se aplicó un cuestionario digital semiestructurado a los maestros de educación básica de las escuelas públicas del municipio de Parobé en el estado de Rio Grande do Sul. Con el objetivo de enumerar las acciones tomadas por los asesores educativos ante los problemas observados en el contexto escolar. e identificar cómo estas acciones pueden contribuir o incluso dañar el proceso de enseñanza-aprendizaje de los estudiantes. Muchos docentes tienen dudas sobre el rol del Asesor y esto les dificulta actuar con los alumnos, ya que situaciones que necesitarían su intervención pueden terminar siendo desatendidas, ya que no son llevados al Asesor. Finalmente, se observó la importancia de establecer una relación armónica entre los sujetos que componen la comunidad escolar para que el trabajo de todas las partes involucradas se pueda realizar de manera más efectiva y satisfactoria.

Palabras clave: Orientación educativa; Acción docente; Asistencia eficaz; Enseñanza.

\section{Introdução}

Para compreendermos melhor qual é a verdadeira função do Orientador Educacional na Escola buscamos uma definição mais precisa do termo "Orientação Educacional", dessa forma observamos que alguns teóricos voltam tal expressão 
para um viés psicológico e terapêutico; outros tendem para o lado pedagógico; e outros, ainda, relacionam com o trabalho de orientação vocacional. Estes fazeres transitam entre o trabalho com alunos com dificuldade e seu ajustamento social, a orientação voltada para escolha profissional ou à formação integral, até a preocupação com a maturidade dos alunos e sua preparação para o futuro. Para Nérici (1983, p. 42) a Orientação Educacional

[...] é o trabalho conjugado de todos os membros de uma escola, coordenados por um orientador, junto ao educando, a fim de levá-lo a realizar da melhor forma possível e sob todos os aspectos, com base na sua realidade biopsicossocial, tendo em vista integrá-lo na sociedade, com base em uma atividade profissional, para torná-lo um cidadão consciente, eficiente e responsável. Esses diferentes conceitos apresentados, de modo geral, variam de acordo com o trabalho executado pelo orientador educacional, isto é, está relacionado ao seu fazer ou àquilo que se espera que ele faça em determinado momento.

Grinspun (2006) leva em consideração a trajetória histórica do orientador educacional no Brasil, partindo, inicialmente, de um enfoque mais psicológico, que ressalta o ajustamento do aluno à escola, à família e à sociedade, para se firmar, hoje, numa dimensão pedagógica, com ênfase num conhecimento que promova/possibilite a transformação/ emancipação do sujeito, da escola e da própria sociedade. Ainda destacamos a colocação de Chagas (2018):

A trajetória da orientação educacional no Brasil surge sobre as influências da orientação norte americana e da orientação francesa, no início da década de 20, na capital paulista. Sobre a influências desses mesmos modelos, a orientação educacional, passa a ser desenvolvida na escola, com a função de adequar a conduta e o comportamento da criança à sociedade.

Seguindo esse pensamento, percebemos a importância de refletirmos sobre o percurso transcorrido pela Orientação Educacional no Brasil, bem como a parte legislativa que orienta suas ações, pois essas iniciativas tornam possível a compreensão das mudanças que foram ocorrendo, e como elas estão ligadas ao ensino e a administração das escolas. Lembrando que esse processo influencia na formação integral do aluno, pois a educação também compreende a vida em sociedade (Wuoters \& Santos, 2019).

Segundo Garcia (2017) a Orientação Educacional tem início no Brasil vinculada ao trabalho e não a educação, só mais tarde cria-se em São Paulo uma emenda que direciona o Orientador como responsável em encaminhar os alunos para o mercado de trabalho, orientando-os conforme suas potencialidades. Corrêa (2016) escreve que:

Repensando a educação, entende-se que as ações sociais precisam ser renovadas e ampliadas conforme as necessidades da sociedade. Dessa forma, não podemos pensar no futuro com as mesmas ideias do passado. Somente com a participação de todos os sujeitos da comunidade escolar, refletindo, de forma decisiva e deliberada, as questões educacionais, podemos tornar realidade o sonho de formar cidadãos plenos, sabedores dos seus direitos e deveres e participativos para a melhoria de suas comunidades.

A Lei de Diretrizes e Bases da Educação (9394/96) diz, no artigo 10: "será instituída obrigatoriamente a Orientação Educacional, incluindo aconselhamento vocacional em cooperação com os professores, a família e a comunidade". Fischman \& Sales (2010) relatam que nós, enquanto professores, sabemos que não podemos transformar o mundo por meio da educação, mas, ainda assim, nos sentimos comprometidos a intervir, provavelmente não de forma satisfatória, mas de maneira simples e aproximadora, buscando dessa forma preservar em nós mesmos as possibilidades de transformar o mundo através da educação.

A importância da abordagem deste tema da área de educação, especificamente a Orientação Educacional, permite uma visão para ação do profissional e o quanto este, pode colaborar junto aos professores, corpo docente e familiares para caminhar rumo às expectativas e necessidades de todos envolvidos no processo de educar.

Partindo da realidade em que vivemos hoje, Grinspun (2006, p. 18) observa que se antes cabia ao orientador ser uma 
figura 'neutra' no processo educacional, para 'guiar os jovens em sua formação cívica, moral e religiosa', hoje, espera-se um profissional comprometido com sua área, com a história de seu tempo e com a formação do cidadão.

Em consonância com Grinspun (2006), acreditamos na definição da orientação educacional como uma prática que deve ocorrer dentro da escola, mas que pode e deve ultrapassar seus muros; uma prática que caminha no sentido da objetividade, da subjetividade e da totalidade da Educação, inserida na busca das finalidades de um Projeto Político Pedagógico, formulado para a escola, em favor de seus próprios alunos. Nesse sentido:

A Orientação Educacional deve ter como eixo de seu trabalho o aluno, não só o aluno que já apresenta problemas, mas todos os educandos, buscando equidade nesse processo de auxílio ao educando. Mas o orientador deve inserir-se na escola como um todo, pois o aluno é um ser bio-psico-social e está inserido numa sociedade da qual a escola é também parte (Barbosa; Lima; Lima; 2011, p.78).

Chagas (2018) salienta que a função do orientador com relação à família do aluno, não é apontar desajustes ou procurar os pais apenas para delinear longas reclamações sobre o comportamento do filho, mas sim, encontrar formas alternativas, juntamente com a família, para que o ambiente escolar seja receptivo ao aluno. Com isso cabe ao orientador a tarefa de identificar problemas e/ou dificuldades emocionais ou psicológicos e, a partir disso, direcionar o seu trabalho para os aspectos saudáveis da vida de seus alunos.

\section{Metodologia}

A pesquisa se caracteriza por ser de cunho qualitativo, para Lüdke \& André (1986) esse tipo de abordagem tem o ambiente como fonte direta de coleta dos dados, sendo o pesquisador seu principal instrumento; a coleta de dados é predominantemente descritiva; o processo pelo qual se desenvolvem as atividades e os procedimentos são tão ou mais importantes que os resultados alcançados e a análise dos dados tende a seguir um processo intuitivo.

Para Neves (2015) a pesquisa qualitativa tem como principal objetivo interpretar o fenômeno em observação. Logo, "pesquisar qualitativamente é não abrir mão da observação, análise, descrição e compreensão do fenômeno a fim de entender seu significado" (Neves, 2015, p. 20). Por ser uma análise intuitiva o pesquisador dificilmente terá certeza de algo antes de iniciar a pesquisa, o que fará com que ele possa ser influenciado pelos resultados que esta apresentar.

Segundo Neves (2015) na pesquisa qualitativa, os participantes são escolhidos por analogia, isto é, similaridade. É uma amostragem baseada em critérios. A amostra é importante porque é a partir dela que o pesquisador chegará a conclusões consistentes em relação à pesquisa realizada. Caso os envolvidos na pesquisa sejam muitos, o melhor é optar pela amostra. Com o objetivo de analisar de que forma a Orientação Educacional está sendo desenvolvida nas Escolas, escolhemos como sujeitos da pesquisa um grupo de professores do município de Parobé, no Estado do Rio Grande do Sul, para os quais foi encaminhado, via formulário no Google Drive, um questionário semiestruturado, apresentado no Quadro 1 que segue: 
Quadro 1.

\section{Questionário:}

Esse questionário foi criado com o objetivo de analisar de que forma a Orientação Educacional está sendo desenvolvida nas Escolas.

1. Você sabe qual é o papel do Orientador Educacional no contexto escolar?

2. O orientador educacional da sua escola realiza intervenções de forma satisfatória?

3. O Orientador Educacional de sua escola toma ações preventivas para evitar problemas futuros ou só se envolve com os alunos quando a situação já está saindo do controle?

4. Quando você precisou procurar o Orientador Educacional foi atendido adequadamente?

5. O Orientador Educacional de sua escola oferece fácil acesso aos professores?

6. Os alunos aparentemente sabem qual o papel do Orientador Educacional na escola?

7. Que medidas você acha que poderiam ser tomadas pela escola para que houvesse um efetivo envolvimento entre o orientador educacional, o professor e os alunos?

Fonte: Autores (2020).

A escolha pelo questionário foi principalmente embasada nos pontos fortes dessa técnica de coleta de dados. De acordo com Gil (1999), entre estes pontos podemos destacar, a garantia do anonimato dos participantes, questões objetivas e de fácil pontuação, baixo custo, facilidade de conversão dos dados para arquivos de computador e ainda deixar em aberto o tempo para que os envolvidos na pesquisa pensem sobre suas respostas. O questionário, segundo Gil (1999, p. 128), pode ser definido "como a técnica de investigação composta por um número mais ou menos elevado de questões apresentadas por escrito às pessoas, tendo por objetivo o conhecimento de opiniões, crenças, sentimentos, interesses, expectativas, situações vivenciadas etc.".

Para essa pesquisa, optou-se pelo uso de um questionário com um número relativamente pequeno de perguntas, porque, além da natureza da técnica um dos pontos negativos é que, questionários muito extensos apresentam alta probabilidade de não serem respondidos, segundo Gil (1999). Os questionários aplicados na pesquisa foram elaborados com perguntas abertas. As perguntas abertas são aquelas que permitem liberdade ilimitada de respostas ao informante. Nelas poderá ser utilizada linguagem própria do respondente. Elas trazem a vantagem de não haver influência das respostas préestabelecidas pelo pesquisador, pois o informante escreverá aquilo que lhe vier à mente. Um dificultador das perguntas abertas 
é também encontrado no fato de haver liberdade de escrita: o informante terá que ter habilidade de escrita, de formatação e de construção do raciocínio.

\section{Resultados e Discussão}

A primeira questão do questionário teve como intuito conhecer os sujeitos da pesquisa, onde questionamos sobre qual função o profissional desempenha na escola, de 13 entrevistados constatamos que 12 são professores de séries iniciais e finais do ensino fundamental e um é diretor da Escola, como apresentado no Gráfico 1 que segue:

Gráfico 1. Identificação dos sujeitos da Pesquisa.

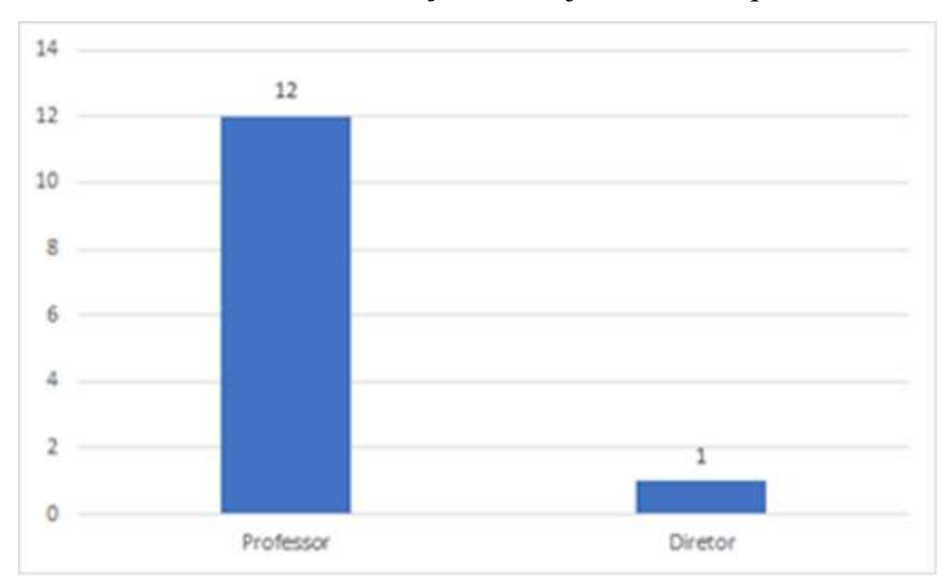

Fonte: Autores (2020).

A segunda questão buscou visualizar se esses profissionais sabem qual é o papel do Orientador Educacional no contexto escolar, para tanto solicitamos que citassem algumas funções que acreditassem ser do trabalho de um Orientador Educacional, para que dessa forma pudéssemos analisar se esses profissionais realmente compreendem a função dessa profissão na Escola. Dos 13 entrevistados, apenas oito responderam a essa questão, destes 1 disse não saber qual a função do Orientador, apesar de ser um número pequeno, melhor seria se não existisse, pois é preocupante um professor não saber ao menos uma função do seu Orientador Educacional.

Já os outros sete afirmaram saber quais são as funções do Orientador na Escola, destacando algumas, como o "atendimento aos pais, alunos e professores"; "orientar professores e alunos sobre o que fazer quando ocorrer algum problema"; "acompanhar e orientar a tarefa docente, acompanhar e orientar o processo de aprendizagem e desempenho do corpo discente"; "Auxiliar no planejamento e orientar o ser docente na realização de projetos e avaliar as funções desenvolvidas pelo mesmo"; "Orientar a prática pedagógica e intervir quando necessário, intermediando o relacionamento entre professor, aluno e familiares" e "Auxiliar no desempenho dos alunos, através de conversas com os mesmos e também com a família. Também auxiliar o professor em sua prática diária, incentivando e dando ideias".

As respostas dadas pelos profissionais mostram que os mesmos sabem algumas funções que o orientador educacional pode exercer na escola, pois assim como destacam Grimm e Appio (2009) o orientador é um elo entre educadores, pais e estudantes, atuando para administrar diferentes pontos de vista. Também trabalha para intermediar os conflitos escolares e ajudar os professores a lidar com alunos com dificuldade de aprendizagem

Ao serem questionados se consideram que o Orientador Educacional da escola realiza intervenções de forma satisfatória. Dez profissionais responderam, destes cinco responderam sim, dois às vezes e três responderam que não, essas respostas encontram-se no Gráfico 2 que segue: 
Gráfico 2. Respostas a Questão 3 do Questionário: “O orientador educacional da sua escola realiza intervenções de forma satisfatória?"

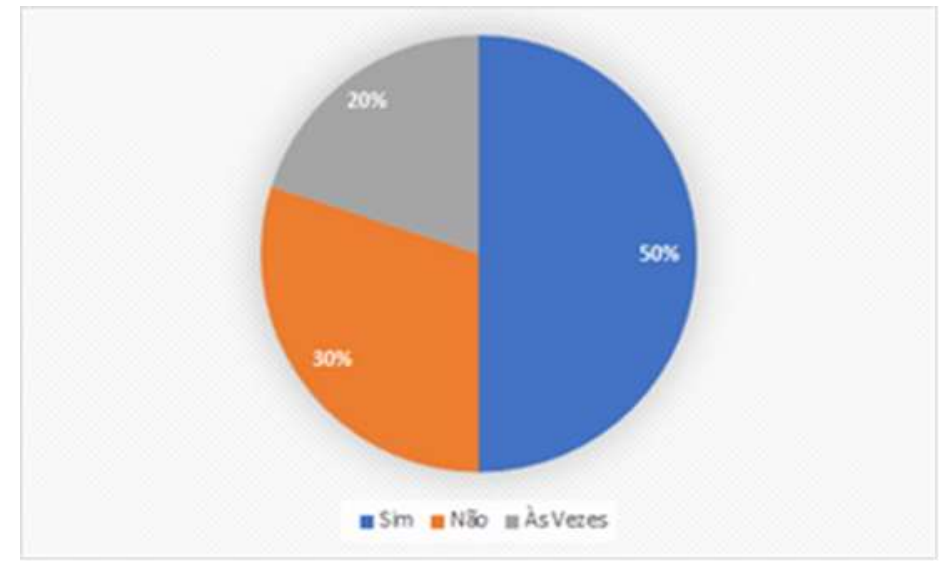

Fonte: Autores (2020).

Os profissionais que responderam sim e destacaram que "é de extrema importância o orientador ter um vínculo com os envolvidos para que o resultado seja satisfatório"; "Em minha escola temos o Supervisor escolar, que sempre está disposto a colaborar, mas acumula outras funções dentro da gestão escolar e, portanto não consegue fazer um acompanhamento contínuo de cada professor e das turmas, somente quando solicitado."; "O mesmo está sempre presente no dia a dia, auxiliando e contribuindo com novas aprendizagens. Pois é muito importante, de forma que o Orientador nos dá parâmetros para que possamos seguir".

Os professores que responderam às vezes enfatizam que "Falta interesse em resolver os problemas"; "Falta um pouco de dedicação". Já os profissionais que responderam que o Orientador não exerce sua função de forma efetiva destacam que “das vezes que precisou do auxílio do Orientador, o mesmo deixou a desejar" e ainda salientam que "é mais Orientador de 'gabinete', pois está muito envolvido com atividades aleatórias". Percebemos nas respostas um certo conflito entre os profissionais da escola, com isso defendemos o estabelecimento de relações mais harmoniosas entre os mesmos, como diálogos mais abertos e soluções conjuntas.

Lück (2002) observa que o agrupamento de funções e atribuições específicas a cada especialidade, determinadas por diferentes interesses, geraram conflitos e falta de comunicação entre os diversos profissionais da escola. Para mudar esta situação, seria preciso observar os princípios que fundamentam o funcionamento do sistema escolar e propiciar medidas que promovessem a integração e a cooperação entre os diferentes profissionais.

Quando foram questionados se o Orientador da escola toma ações preventivas para evitar problemas futuros ou só se envolve com os alunos quando a situação já está saindo do controle, houve 12 respostas, que podem ser verificadas no Gráfico 3 que segue: 
Gráfico 3. Respostas a Questão 4 do Questionário: "O Orientador Educacional de sua escola toma ações preventivas para evitar problemas futuros ou só se envolve com os alunos quando a situação já está saindo do controle?"

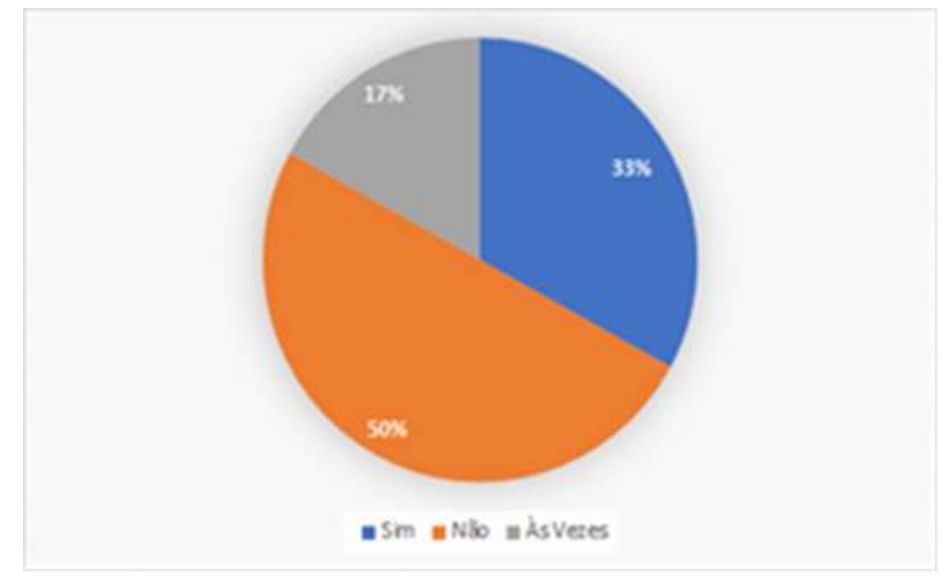

Fonte: Autores (2020).

Destes 12 respondentes quatro confirmaram que são tomadas algumas medidas preventivas, como conversa com alunos que tem decaído na escola, chamada de responsáveis e também conversas com os professores. Dois profissionais disseram que na maioria das vezes o Orientador consegue tomar ações preventivas. Já seis profissionais explanaram que o orientador só se envolve quando a situação está saindo do controle ou quando lhe é solicitado, ocorrendo uma intervenção normalmente quando o professor está sem alternativa, e precisa de ajuda para conter a situação.

$\mathrm{Na}$ quinta questão quando foram indagados se precisaram procurar o Orientador Educacional e se foram atendidos adequadamente, houve 9 respostas, as quais podem ser verificadas no Gráfico 4 que segue:

Gráfico 4. Respostas a Questão 5 do Questionário: "O Orientador Educacional de sua escola oferece fácil acesso aos professores?"

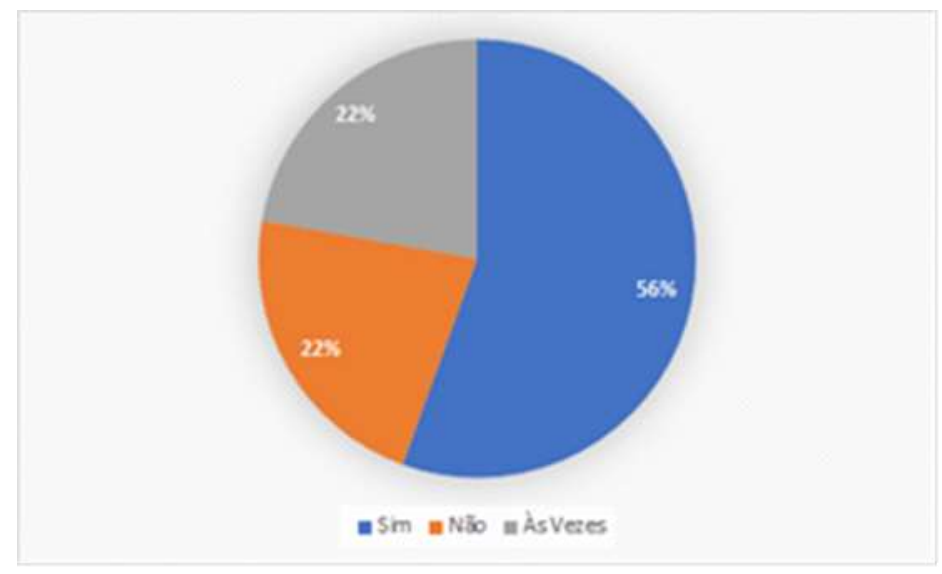

Fonte: Autores (2020).

Destes nove profissionais, cinco responderam que sempre que solicitaram auxílio do Orientador Educacional tiveram um retorno positivo. Dois profissionais destacaram que na maioria das vezes foram atendidos adequadamente. Já dois profissionais enfatizaram que ao buscar ajuda do orientador não foram atendidos satisfatoriamente.

Seis profissionais responderam a sexta questão que indagava se o Orientador Educacional da escola oferecia fácil acesso aos professores. Todos os respondentes afirmaram que sim, destacando que "o orientador é bem comunicativo e amigo de todos"; "Está sempre circulando pela escola, quando não está em atendimento" e "Sua sala está sempre à disposição dos 
professores ou até mesmo quando não se consegue vê-lo, falamos pelo WhatsApp".

Ao serem indagados se "Os alunos aparentemente sabem qual o papel do Orientador Educacional na escola?", houve nove respondentes, as respostas podem ser observadas no Gráfico 5 que segue:

Gráfico 5. Respostas a Questão 7 do Questionário: "Que medidas você acha que poderiam ser tomadas pela escola para que houvesse um efetivo envolvimento entre o orientador educacional, o professor e os alunos?"

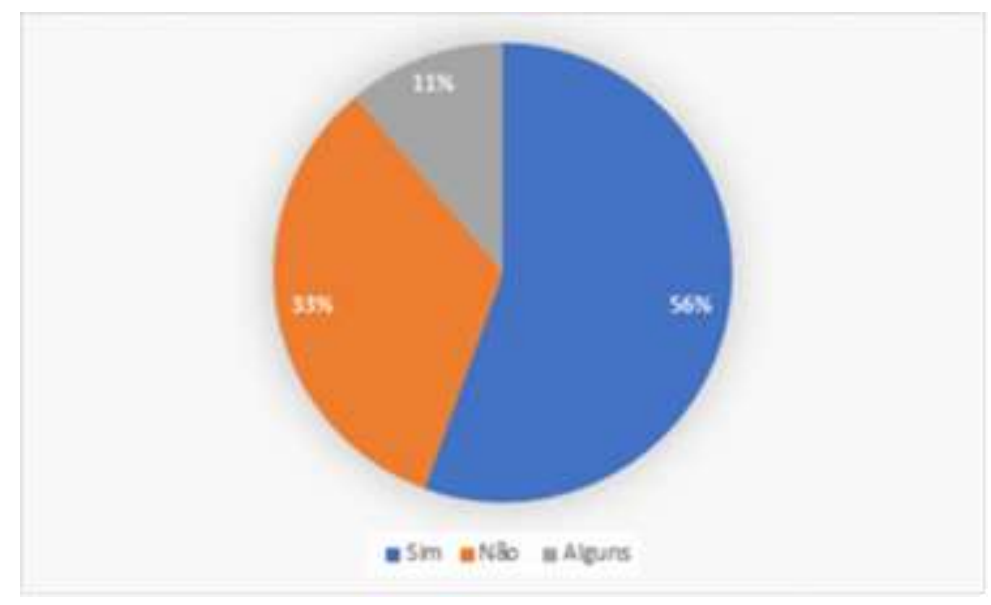

Fonte: Autores (2020).

Destes nove profissionais, cinco afirmaram que os alunos não sabem qual o papel do orientador educacional, como podemos ver na fala de um professor "Acredito que isso deveria ser mais esclarecido a eles, pois a grande maioria pensa que o orientador serve apenas para resolver conflitos, que só atende os casos de indisciplina". Três profissionais responderam que os alunos sabem o papel do Orientador na Escola, onde um professor ressalta que o "Orientador Educacional sempre deixa bem claro sua função dentro da escola”. E um profissional enfatiza que apenas alguns alunos reconhecem o papel do Orientador Educacional na escola.

Observando as respostas a esse questionamento percebemos a importância de haver um comprometimento de todas as partes envolvidas no processo de ensino-aprendizagem, pois segundo Grimm e Appio (2009) é função da escola criar relações de qualidade que permitam aos alunos conviver democraticamente, respeitando tanto os princípios institucionais da escola, quanto abrindo possibilidades para o desenvolvimento de sua cidadania.

A realização de um processo educativo de qualidade, segundo Libâneo (2019) e Grinspun (1998), passa pela formação permanente dos profissionais que atuam na escola. Com o objetivo de garantir a qualidade no ensino e nas relações que se estabelecem no âmbito escolar, cabe ao orientador educacional desenvolver ações voltadas ao processo de formação continuada dos profissionais que atuam na escola, pois para dar conta da complexidade do mundo moderno, que está em constante mudança, é preciso estar reatualizando, revendo, repensando a prática educativa e os pressupostos que fundamentam esta prática.

Aos serem questionados sobre "Que medidas acham que poderiam ser tomadas pela escola para que houvesse um efetivo envolvimento entre o orientador educacional, o professor e os alunos?", houve treze respondentes, algumas respostas encontram-se na sequência:

"Seria interessante, pelo menos uma vez por trimestre, o orientador entrar nas salas, esclarecer seu papelffunção dentro da escola, realizando momentos de conversas, debates e técnicas motivacionais." 
Não sei.

Seria i interessante, pelo menos uma vez por trimestre, o orientador entrar nas salas, esclarecer seu papelffunção dentro da escola, realizando momentos de conversas, debates e técnicas motivacionais.

Maior envolvimento com os professores e alunos.

Ter momentos de diálogos fora da sala de aula.

Organizar encontros com as turmas, interagindo e colocando o orientador a disposição para eventuais dificuldades que os alunos estejam passando tanto na escola, quanto em casa. Aos professores poderiam ser destinados encontros periodicamente para acompanhar o progresso e as dificuldades, buscando em conjunto soluções para as mesmas.

Encontros no decorrer do semestre e a participação do Orientador em projetos que envolvam ambas as partes.

Bom, começaria traçando um relacionamento mais próximo entre alunos e o orientador, esclarecendo que ele está ali pra ajudar a desenvolver as potencialidades de cada um.

O professor deveria ter mais tempo para conversar com o orientador. Normalmente sempre estamos correndo contra o tempo.

Mais diálogo entre as partes

Mais momentos para conversas, em que o orientador entre na sala de aula, interagindo com ambas as partes.

Primeiramente, de início, apresentar-se como tal, e explicitar suas funções.

Um maior esclarecimento sobre as funções do orientador, tanto pra professores, quanto para os alunos. Assim leva nos a uma liberdade maior de procurá-lo.

Percebemos nas respostas dos profissionais que os mesmos consideram o Orientador Educacional uma peça essencial no contexto escolar e que para o trabalho de todas as partes ocorrer de forma satisfatória é necessário que cada um saiba suas funções e que interajam e se comuniquem para o trabalho ocorrer de forma efetiva. Para que o processo de ensinoaprendizagem se concretize ele precisa ser integral e humanizado, buscando por uma formação mais cidadã, para que os alunos se sintam participantes nesse processo.

Para que isso ocorra é necessário que os orientadores educacionais, de acordo com Lück (2017), tenham conhecimento de como ocorre o processo de desenvolvimento humano; saber como ocorre a aprendizagem; saber que o ambiente social, econômico e cultural exerce influências sobre o desenvolvimento do aluno; ter respeito às diferenças individuais; desenvolver habilidades de relacionar-se de modo humano, resolver os problemas de sala de aula; motivar os alunos; selecionar e desenvolver formas adequadas de ensino; trabalhar de modo cooperativo e em função dos interesses e necessidades dos alunos; e, ainda, conheçam as políticas educacionais que guiam a educação no país e estejam abertos a compartilhar estes conhecimentos com os outros profissionais que atuam na escola. Pois, segundo Grimm \& Appio (2009) a busca pelo desenvolvimento humano implica no modo como as relações são construídas.

\section{Considerações Finais}

Diante dessa pesquisa qualitativa aplicada através de questionários, podemos relatar que o orientador precisa estar comprometido com a formação dos seus alunos, considerando sempre o diálogo com os professores, pois são eles que passam a maior parte do tempo com os alunos. E além da formação cognitiva e pedagógica proporcionada pelo professor, enquanto mediador desse processo, também ocorre a formação do caráter social e psicológico.

É preciso compreender, que "a orientação educacional é parte de um todo, faz parte da escola que com ela interage permanentemente, assim como com a própria sociedade" (Grinspun, 2003, p. 70). A escola é uma instituição social, que tem como uma de suas atribuições fazer com que o aluno amplie seus saberes, adquira hábitos saudáveis e valores integrantes da 
vida humana. O Orientador Educacional tem como função atender e acompanhar a vida escolar dos alunos e cuidar do relacionamento entre escola, pais e comunidade.

A revitalização desta função consiste em mudar as velhas práticas, observando as mudanças que estão ocorrendo na sociedade como um todo. Cabe a este profissional assumir novos papéis, fundamentalmente o de articulador da construção de práticas pedagógicas voltadas para a emancipação do sujeito, promovendo situações de ensino e aprendizagem adequadas e criando condições favoráveis para o pensar, o refletir e o dialogar com os saberes.

Uma forma de contribuir para que esse trabalho entre professores, orientadores educacionais e alunos, seja mais efetivo, seria revisitar a escola, propondo reuniões, palestras, formações continuadas, onde esses profissionais e até mesmo os estudantes pudessem expor suas ideias e dialogar de forma harmoniosa, buscando soluções em conjunto para melhorar o relacionamento dentro da comunidade escolar.

\section{Referências}

Barbosa, C. C., Lima, N. S., \& Lima, E. B. (2011). As contribuições da Orientação Educacional no processo ensino-aprendizagem. Revista Brasileira de Informações Científicas. 2(1).

Bauman, Z. (1998) Globalização: consequências humanas. Universidade da Colômbia.

Brasil. Lei de Diretrizes e Bases da Educação Nacional. LDB 9394/1996.

Chagas, G. M. E. (2018). Educação: um processo de humanização. Revista Research, Society and Development, v. 7.

Fischman, G. Sales, S. (2010). Formação de professores e pedagogias críticas. É possível ir além das narrativas redentoras? Revista Brasileira de Educação.

Garcia, R. L. (2002) Orientação Educacional: o trabalho na escola. (4a ed.), Loyola.

Giacaglia, L. R. A, \& Penteado, W. M. A. (2011). Orientação Educacional na prática. (6a ed.), Cengage Learning.

Gil, A. C. (1999). Métodos e técnicas de pesquisa social. (5a ed.), Atlas.

Gil, A. C. (2002). Como elaborar projetos de pesquisa. (4a ed.), Atlas.

Grimm, V, Appio, C. R. (2009) Orientação Educacional. Centro Universitário Leonardo da Vinci. Grupo UNIASSELVI.

Grinspun, M. P. S. Z. (1998) A prática dos orientadores educacionais. Cortez.

Grinspun, M. P. S. Z. (2003) Supervisão e orientação educacional: perspectiva de integração na escola. Cortez.

Grinspun, M. P. S. Z. (org.). (2003). A Orientação Educacional, conflitos e paradigmas e alternativas para a escola. (4a ed.), Cortez.

Libâneo, J. C. (2004) Organização e gestão da escola: teoria e prática. Alternativa.

Libâneo. J. C. (2019) Organização e Gestão da Escola Teoria e Prática. (7a ed.), Heccus.

Lück, H. (2002). Ação integrada: administração, supervisão e orientação educacional. (19a ed.), Vozes.

Lück, H. (2017) Planejamento em Orientação Escolar. (23a ed.), Vozes.

Lüdke, M., \& André, M. (2013). Pesquisa em educação: abordagens qualitativas. (2a ed.).

Lüdke, M., \& André, M. (2013). Pesquisa em educação: abordagens qualitativas. (2a ed.),

Nérici, G. I. (1983). Introdução à orientação educacional. (4a ed.), Atlas.

Neves, J. L. (2015). Pesquisa Qualitativa. Características, uso e possibilidades. Cadernos de Pesquisas em Administração, São Paulo.

Vasconcellos, C. S. (2002). Coordenação do trabalho pedagógico: do projeto político-pedagógico ao cotidiano da sala de aula.

Wouters, J. A. D, \& Santos, E. A. G. (2019) A Orientação Educacional no Brasil e o contexto da rede municipal de ensino de Santa Maria, RS. Revista Research, Society and Development, 8(4). 